BEduManageRs Journal

Borneo Educational Management and Research Journal, Vol.1, No.1, 2020

ISSN: 2747-0504

\title{
Evaluasi Implementasi Kebijakan Otonomi Pendidikan Dari Dinas Pendidikan Kabupaten/Kota Ke Dinas Pendidikan Propinsi Kalimantan Timur
}

\author{
Sjachruddin M. Seman ${ }^{1}$, Husainie Usman ${ }^{2}$, Johansyah $^{3}$ \\ Universitas Mulawarman \\ e-mail: doktormp@fkip.unmul.ac.id
}

\begin{abstract}
The objectives of the research are to: (1) find out the effectiveness of the implementation of education autonomy policy from regency / city to province; (2) to know the effectiveness of the realization of education budget; (3) to know the effectiveness of quality improvement of education quality; (4) to know politicization; And (5) finding new strategies for implementing education autonomy policies. The study used the Tyler model evaluation study. Level of effectiveness using percentages. Qualitative data were analyzed with McMilland model. The validity of qualitative data uses credibility, dependability, transferability, and confirmability. The study concluded: (1) the implementation of education policy autonomy is about $50 \%$ (quite effective), qualitatively ineffective; (2) the realization of the education

budget is $25 \%$ (not effective) and also qualitatively ineffective; (3) teacher quality improvement $65.30 \%$ (effective), qualitatively ineffective; (4) teacher politicization hampers the professionalism and career development of teachers, shifts the politicization of teachers from districts / municipalities to the politics of what, when, and how to get something, no true friend of true interest, art of possibility, way; (5) the new strategy for streamlining the implementation of education autonomy policy is $8 K$ in bebaya.
\end{abstract}

Keywords: evaluation, policy, education autonomy.

\section{Pendahuluan}

Berdasarkan pengamatan awal ke tempat penelitian diperoleh kenyataan (das sein) antara lain sebagai berikut.

1. Implementasi kebijakan otonomi pendidikan dari Kabupaten/Kota ke Propinsi belum efektif.

2. Realisasi anggaran pendidikan oleh propinsi belum efektif, terlambat, dan masih kurang.

3. Peningkatan kualitas pendidikan belum efektif.

4. Politisasi guru yang selama ini menghambat profesionalisme dan pengembangan karier guru.

5. Belum ada strategi baru untuk merevisi implementasikan kebijakan otonomi pendidikan.

Harapan peneliti (das sollen) adalah sebagai berikut.

1. Implementasi kebijakan otonomi pendidikan dari Kabupaten/Kota ke Propinsi efektif.

2. Realisasi anggaran pendidikan efektif, tepat waktu, dan memadai.
3. Peningkatan kualitas pendidikan efektif.

4. Politisasi guru dikurangi agar tidak menghambat profesionalisme dan pengembangan karier guru.

5. Ditemukannya strategi baru untuk merevisi implementasikan kebijakan otonomi pendidikan.

Penelitian tentang evaluasi implementasi kebijakan otonomi pendidikan dari Kabupaten/Kota ke Propinsi belum pernah dilakukan. Evaluasi resmi dari pihak pemerintah juga belum ada (Kompas, 3 Februari 2017). Secara teoretis, minimal ada sepuluh definisi evaluasi menurut para ahlinya. Tetapi definisi evaluasi pada penelitian ini memilih evaluasi secara yuridis karena kebijakan adalah pembuatan keputusan berdasarkan yuridis (Anonim, 2016). Penelitian ini melanjutkan hasil penelitian Federasi Serikat Guru Indonesia (PSGI) pada tahun 2012 di 29 kabupaten/kota yang menemukan 81,25 persen guru di 29 kabupaten/kota masih memiliki kompetensi yang sangat rendah. 
BEduManageRs Journal

Borneo Educational Management and Research Journal, Vol.1, No.1, 2020

ISSN: 2747-0504

\section{KAJIAN TEORI}

Kebijakan (policy) adalah melaksanakan tugas sesuai peraturan perundang-undangan yang berlaku (Anonim, 2016). Dunn (1984:110) mengemukakan tiga elemen sistem kebijakan yaitu: pelaku, lingkungan, dan kebijakan publik. Noeng Muhadjir (1993:38, 2000:34-35, dan 2004:93-94) menyatakan ada enam tingkatan kebijakan yaitu tingkat idiil, politik-strategik, profesional, eksekutif, administrasi, dan operasional.

Tujuan kebijakan otonomi pendidikan dari Dinas Pendidikan Kabupaten/Kota ke Dinas Pendidikan Provinsi adalah:

(1) agar pemerintah kabupaten/kota lebih fokus membenahi pendidikan dasar, Pendidikan Anak Usia Dini (PAUD) serta pendidikan masyarakat (dikmas);

(2) untuk memudahkan pemerintah provinsi menyeragamkan kebijakan pengelolaan sekolah, memprioritaskan pendidikan menengah, dan menuntaskan program pemerintah wajib belajar 12 tahun.

(3) mempercepat terwujudnya kesejahteraan masyarakat melalui peningkatan pelayanan, pemberdayaan dan peranserta masyarakat, serta daya saing daerah dengan menggunakan prinsip demokratis, pemerataan, keadilan, dan kekhasan suatu daerah dalam sistem Negara Kesatuan Republik Indonesia.

(4) pemerataan tanggung jawab yang memberikan kontribusi pemerataan mutu dan peningkatan angka partisipasi kasar. Pemerintah Kabupaten/Kota fokus pada pengelolaan pendidikan dasar, pendidikan anak usia dini, dan pendidikan masyarakat. Kebijakan pemerintah provinsi pun akan menjadi seragam dalam mengelola pendidikan menengah.

(5) agar pengelolaan SMA/SMK lebih efektif dan profesional (Wakil Ketua Panitia RUU Pemerintah Daerah di DPR).

(6) menegakkan prinsip proporsionalitas beban pelayanan kepada masyarakat di tiap lini pemerintahan. Pembagian kewenangan yang proporsional dengan sendirinya menopang kelincahan bergerak dalam pelayanan masyarakat (Nur Sadik, 2017: 15).

Menurut Dunn (1994:24), pembuatan kebijakan dengan tahap:
(1) penyusunan agenda, (2) formulasi kebijakan, (3) adopsi kebijakan, (4) implementasi kebijakan, dan (5) evaluasi kebijakan.

Pasal 18 ayat (2) dan ayat (5) UUD 1945 menyatakan bahwa Pemerintahan Daerah berwenang untuk mengatur dan mengurus sendiri Urusan Pemerintahan menurut asas Otonomi dan Tugas Pembantuan dan diberikan otonomi yang seluas-luasnya. Otonomi daerah adalah memberi kewenangan untuk mengatur dan mengurus sendiri Urusan Pemerintahan yang diberikan oleh Pemerintah Pusat kepada Daerah sesuai aspirasi dan kepentingan masyarakatnya sepanjang tidak bertentangan dengan tatanan hukum nasional dan kepentingan umum (UU No. 23 tahun 2014). Definisi evaluasi dikemukan Jemari Mardapi (2016), Stuflebeam \& Shinkfield (1958), Warthen \& Sanders (1973), Kaufman \& Thomas (1980), Brikerhoff, et al. (1986), Stufflebeam (2003), McDavid \& Hawthorn (2006). Tujuan evaluasi adalah untuk mengetahui tingkat efektivitas implementasi program (Weiss (1972:4; Kaufman \& Thomas (1980: 5); Stufflebeam (2003: 4); Nana Syaodih Sukmadinata (2005:121) Fitzpatrick, Sanders, \& Worthen (2011: 13; 2004; 10).

\section{METODE PENELITIAN}

Metode penelitian menggunakan pendekatan kuantitatif dengan jenis penelitian evaluasi dan pendekatan kualitatif dengan jenis studi kasus. Evaluasi dipilih karena untuk merevisi (Dunn, 2003). Studi kasus dipilih untuk menyelesaikan kasus implementasi kebijakan (McMillan, 2004 \& Cresswel, 2014). Penelitian evaluasi menggunakan model Tyler. Model ini dipilih karena sederhana, mudah dimengerti, mudah dilaksanakan, serta menghasilkan informasi yang cocok dengan misi pembuat kebijakan (Fitzpatrick, Sanders, \& Worthen, 2011:166). Model Tyler dilakukan dengan membandingkan indikator tujuan dengan realisasi yang diperoleh. Tingkat efektivitas didapat dengan membandingkan persentase yang diperoleh dengan kriteria efektivitas.

Pendekatan kualitatif menggunakan langkah-langkah dan analisis model McMilland (2014). Model ini dipilih karena komprensif, mutakhir, dan praktis. Keabsahan data dilakukan melalui kredibilitas, transferabilitas, dependabilitas, dan konfirmabilitas. 
BEduManageRs Journal

Borneo Educational Management and Research Journal, Vol.1, No.1, 2020

ISSN: 2747-0504

\section{HASIL DAN PEMBAHASAN}

Implementasi otonomi kebijakan pendidikan dari Dinas Pendidikan Kabupaten/Kota ke Dinas Pendidikan Provinsi sekitar 50\% (cukup efektif). Secara kualitatif tidak efektif karena: implementasi tergesa-gesa, belum ada petunjuk teknis, tanpa ujicoba, SDM belum siap, struktur organisasi belum dibuat, anggaran BOS belum cukup, gaji honor guru belum tersedia. Otonomi terjadi karena tuntutan daerah agar daerah diberi otonomi melalui desentralisasi. Desentralisasi dan sentralisasi saling tarik menarik. Jika desentralisasi menguat, muncul tuntutan untuk disentralisasikan. Demikian sebaliknya.

Temuan ini mendukung pendapat pendapat Unifah Rosyidi (2017), tetapi bertentangan dengan pernyataan Menteri Pendidikan dan Kebudayaan (2017).

Realisasi anggaran pendidikan di Dinas Pendidikan Propinsi 25\% (tidak efektif) dan secara kualitatif tidak efektif karena: pencairannya terlambat, belum memadai untuk BOS, dan belum ada untuk guru honor. Hal ini mengancam sekolah gratis dan SPP akan menjadi beban orang tua. Temuan ini mendukung data (Kompas 9 Januari 2017 \& 14 April 2017), Muhadjir Effendi (2017:1).

Peningkatan kualitas guru 65,30\% (efektif). Secara kualitatif tidak efektif karena: bimtek guru bukan jaminan meningkatkan kualitas guru. Jumlah guru berkualitas cukup tetapi distribusinya tidak merata. Distribusi merata jika guru mudah dimutasi. Guru mudah dimutasi jika tidak ada campur tangan keluarga dan kerabat pejabat, mau memindahkan anak ke sekolah tidak favorit, puas dengan fasilitas tempat pindahan, ekonomi, dan mampu beradaptasi budaya setempat. Kesejahteraan guru tidak meningkatkan kualitas guru. Semua kabupaten/kota tidak menganggarkan untuk bimtek guru. Temuan ini mendukung pendapat Irman Yasin Limpo (2017) dan penelitian Federasi Serikat Guru Indonesia.

Politisasi guru menghambat profesionalisme dan pengembangan karier guru dan mungkin hanya memindahkan politisasi guru dari kabupaten/kota ke propinsi; dalam dunia politik berlaku apa, kapan, dan bagaimana mendapatkan sesuatu yang diharapkan, tidak ada teman sejati yang ada kepentingan sejati, seni kemungkinan, dan menghalalkan secara cara. Temuan ini mendukung Kompas (9 Januari 2017; 14 Mei 2017; \& 8 Juni 2017). Strategi baru untuk mengefektifkan implementasi kebijakan otonomi pendidikan adalah $8 \mathrm{~K}$ secara olah bebaya. Kedelapan $\mathrm{K}$ dilakukan dengan cara olah bebaya. Olah artinya mendayung. Bebaya artinya bersama-sama dengan gerak yang sama secara sinerjis. Artinya semua aktor pendidikan bekerja sama secara sinerjik dan terkoordinatif. Temuan ini mendukung motto Pemerintah Propinsi Kalimantan Timur.

\section{KESEIMPULAN}

Penelitian menyimpulkan: (1) implementasi otonomi kebijakan pendidikan sekitar $50 \%$ (cukup efektif), secara kualitatif tidak efektif; (2) realisasi anggaran pendidikan 25\% (tidak efektif) dan secara kualitatif juga tidak efektif; (3) peningkatan kualitas guru $65,30 \%$ (efektif), secara kualitatif tidak efektif; (4) politisasi guru menghambat profesionalisme dan pengembangan karier guru, memindahkan politisasi guru dari kabupaten/kota ke propinsi, dalam dunia politik berlaku apa, kapan, dan bagaimana mendapatkan sesuatu, tidak ada teman sejati yang ada kepentingan sejati, seni kemungkinan, dan menghalalkan segala cara; (5) strategi baru untuk mengefektifkan implementasi kebijakan otonomi pendidikan adalah 8K secara olah bebaya.

Rekomendasi untuk tingkat pusat, Kemendagri sebaiknya segera membuat petunjuk teknis bersama Kemendikbud dan Kemenkeu dengan menerapkan strategi baru $8 \mathrm{~K}$ secara olah bebaya. Rekomendasi untuk Pemerintah Propinsi Kalimantan Timur adalah sebaiknya segera melaksanakan petunjuk teknis tersebut dengan menerapkan strategi baru $8 \mathrm{~K}$ secara olah bebaya pula.

\section{DAFTAR PUSTAKA}

Allen, M. J. \& Yen, W. M. Introduction to Measurement Theory. California: Broks Cole Publishing Company, 1979).

Anonim. Perencanaan Peningkatan Kinerja. (Jakarta: Lembaga Administrasi Negara, 2016).

Alih Kelola SMA/SMK Gagap. Kompas, 9 Januari 2017, halaman 1 dan 15.

Anggaran Dua Puluh Persen, Kompas, 27 Februari 2017: 6. 
BEduManageRs Journal

Borneo Educational Management and Research Journal, Vol.1, No.1, 2020

ISSN: 2747-0504

Arthur Sharplin, Strategic Management, New York: McGraw-Hill, Inc, 1991

Brikerhoff, RD. Brethower, D.M., \& T. Hlucy. Program Evaluation a Practitionare's Guide for Trainers and Educators, (Western Michigan: Kluwer-Nijhoff Publishing, 2004).

Creswell, J.W. Research Design Qualitative, Quantitative, \& Mixed Methods Approach. (London: Sage, 2014).

Direktur Jenderal Pendidikan Dasar dan Menengah Kementerian Pendidikan dan Kebudayaan. Alih Kelola SMA/SMK Gagap. Kompas 9 Januari 2017, halaman 15.

Dunn, N. William, Analisis Kebijakan Publik. (Yogyakarta: Gajah Mada University Press, 2003).

Fitzpatrick, J. L., Sanders, J. R., \& Worthen, B. R. Program Evaluation: Alternative Approaches and Practice Guidelines, $\left(4^{\text {th }}\right.$ ed.). Boston: Pearson Education Inc., 2011).

Griffin, P. \& Nix, P. Educational Assessment and Reporting; A New Approach. (Sydney: Harcourt Brace Jovanovich, 1991).

Husaini Usman. Metodologi Penelitian Sosial (Jakarta: Bumi Aksara, 2017).

Irman Yasin Limpo. Penataan Guru Jadi Prioritas. Kompas 2 Februari 2017, halaman 11.

Issac, S., \& Michael, W. B. Handbook in Research and Evaluation (2 ${ }^{\text {nd }}$ ed). (San Diego California: EDITS Publisher, 1984).

Jemari Mardapi. Pengukuran, Penilaian, dan Evaluasi pendidikan.

Yogyakarta: Nuha Medika, 2016).

Kaufman, R., \& Thomas, S. Evaluation Without Fear. (New York: New Viewpoints, 1980).

Kirkpatrick, D.L., \& Kirkpatrick, J.D. Implementing the Four Level: A Practical Guide for Effective Evaluation of Training Program. (San Francisco: Berrett-Koehler Publishers, Inc, 2007).
Konspirasi, Kompas 14 Mei 2017.

Lexy J. Moleong, Metodologi Penelitian Kualitatif, Edisi Revis (Bandung : Penerbit: Remaja Rosdakarya, 2006).

McDavid, J. C. \& Hawthorn, L. R. L.. Program Evaluation \& Performance Measurement: an Introduction to Practice. (London: Sage Publications, 2006)..

McMillan, J., Educational Research Fundamentals for the Consumer. (New York: Pearson. 2014).

Muhadjir Efendi. "Terjadi Tumpang Tindih Mendikbud Minta Daerah Bertangung Jawab: Kompas 27 Januari 2017, halaman 15.

Noeng H. Muhajir, Metodologi Penelitian Kebijakan dan Evaluation Research, Yogyakarta: Rake Sarakin, 2003

Nur Sadik. "Alih Kelola SMA/SMK Gagap: Kompas 9 Januari 2017: halaman 1.

Orang Tua Tebebani Pungutan, Kompas 13 April 2017.

Plintat Plintut, Kompas 8 Juni 2017.

Royani, A. Mengenal ilmu qiro'at. Perc. (Ogan Ilir: PP. Al-Ittifaqiah Press, 2003).

Rubbert C. Bogdan and Sari Knop Biklen, Qualitative Research for Education, Boston:Allyn and Bacon, 1982

Rufai, S. A. (2010). Reviving contemporary muslim education through Islamicbased teachings and evaluation methods. International Islamic University Malaysia (IIUM) Journal of Islam in Asia, 7, 2187-214.

Stufflebeam, D. L. The CIIP model for evaluation. Portlad (Oregon: Oregon Program Evaluators Network (OPEN), 2003).

Stufflebeam, D. L, Shinkfield, A. J. Systematic Evaluation. (New York: Chestnut Hill: Kluwer-Nijhoff Publishing, 1958).

Unifah Rosyidi. Penataan Guru Jadi Prioritas. Kompas 2 Februari 2017: 11.

Weiss, C.H. (1992). Evaluation Research.

London: Prentice-Hall Inc. 
BEduManageRs Journal

Borneo Educational Management and Research Journal, Vol.1, No.1, 2020

ISSN: 2747-0504

Worthen, B.R \& Sanders, J.R. Educational evaluation: Theory and practice. Ohio: Charles A. Jones Publishing Company Worthington, 1981).

Yarbrough, D.B., et al. (2010). Joint Committee on Standards for Educational Evaluation: The program evaluation standards ( $3^{\text {rd }}$ ed.).(New York: McGrew-Hill Book Company, 2010).

Zhang \& Zeller, et.al. (2011). Using the context, input, process, and product evaluation model (CIPP) as a comprehensive framework to guide the planning, implementation, and assessment of service-learning programs. Journal of Higher Education Outreach and Engagement, 15, 4, 5784. 